\title{
Collapse of Masonry Buttresses
}

\author{
J. A. Ochsendorf ${ }^{1}$; J. I. Hernando ${ }^{2}$; and S. Huerta ${ }^{3}$
}

\begin{abstract}
This paper investigates the collapse of masonry buttresses under concentrated lateral loads. A fracture forms at the collapse state, significantly decreasing the resistance to overturning. Conventional analysis assumes that a masonry buttress acts monolithically to resist lateral loads. The current paper demonstrates that this approach is clearly unsafe, and the possibility of a fracture at the collapse state must be considered in the design and assessment of masonry buttresses. By treating the masonry as a continuum, infinitely strong in compression, with no resistance to tension and no possibility for sliding, the writers demonstrate the form of the fracture and determine the critical failure load for typical buttress forms. This approach follows in the tradition of limit analysis of masonry structures as developed by Heyman. General methods are proposed for the overturning analysis of masonry buttresses, and calculation examples are provided. Finally, methods for evaluating the safety of existing buttresses are presented and discussed.
\end{abstract}

DOl: 10.1061/(ASCE)1076-0431(2004)10:3(88)

\section{Introduction}

The safety of masonry vaulted structures depends on the stability of buttresses to support the thrust of vaults and arches. Although arches have been thoroughly analyzed in the published record, researchers have not sufficiently studied the safety of buttresses. The failure of a buttress will lead to catastrophic collapse, and indeed, the majority of structural design rules of the medieval and Renaissance eras refer to the sizing of buttresses (Heyman 1968, 1995; Huerta 1990, 1999).

The buttress problem is one of simple statics: the overturning moment produced by the thrust of the vault must be equilibrated by the mass of the buttress. Engineers often assume that buttresses are monolithic, with the entire mass of the buttress resisting the lateral forces. This was the usual assumption from the earliest scientific design of buttresses (La Hire 1712; Bélidor 1729), and the assumption continues to be applied today (Boothby 1994; Gilbert and Melbourne 1994). However, a masonry buttress is a series of individual stones placed roughly in horizontal courses and laid with or without mortar between the stones. The material can only transmit compressive forces, and tensile forces will separate the stones because the adhesion provided by the mortar is weak. Thus masonry is a unilateral material. Furthermore, the values of compressive stress are typically very low in traditional masonry construction, and, generally, the material will not fail in compression. Therefore, masonry is con-

\footnotetext{
${ }^{1}$ Assistant Professor, Building Technology, Program, Massachusetts Institute of Technology, Room 5-418, Cambridge, MA 02139.

${ }^{2}$ Assistant Professor, E.T.S. de Arquitectura, Univ. Politécnica de Madrid, Madrid 28040, Spain.

${ }^{3}$ Professor, E.T.S. de Arquitectura, Univ. Politécnica de Madrid, Madrid 28040, Spain.

Note. Discussion open until February 1, 2005. Separate discussions must be submitted for individual papers. To extend the closing date by one month, a written request must be filed with the ASCE Managing Editor. The manuscript for this paper was submitted for review and possible publication on April 17, 2002; approved on May 14, 2004. This paper is part of the Journal of Architectural Engineering, Vol. 10, No. 3, September 1, 2004. CASCE, ISSN 1076-0431/2004/3-88-97/\$18.00.
}

sidered to be rigid and infinitely strong in compression. Finally, the static coefficient of friction is very high, and failure by sliding is unlikely. The above affirmations characterize masonry material and were used, implicitly or explicitly, in the analysis of masonry arches and vaults during the 18th and 19th centuries. Heyman (1966) systematized these assumptions to include masonry arch and vault analysis within the framework of limit analysis.

To apply limit analysis methods, the individual blocks must have sufficient size. It is not possible to build a tall, load-bearing wall of very small blocks, like sand particles. As the block size becomes smaller, it is more likely that the blocks will separate if they are not held in direct compression. This is precisely the case with masonry buttresses. As a consequence of the unilateral character of the material, some fracture of the buttress can be expected at collapse, similar to leaning towers or walls of masonry (Heyman 1992). At the limit of overturning, part of the buttress will remain attached to the base, and a stress-free surface of fracture will form.

The problem is presented in Fig. 1. Under the influence of an inclined lateral load $F_{s}$, a solid masonry buttress will collapse if the applied overturning moment is greater than the stabilizing moment due to the weight of the buttress [Fig. 1(a)]. Assuming horizontal slices, it is possible to draw the line of thrust, i.e., the locus of the force resultants above the plane, within the buttress for the previous collapse load [Fig. 1(b)]. The exact form of the line of thrust depends on the family of slices being considered in the masonry. Milankovitch (1907) presents a detailed discussion of this problem. The current paper considers only horizontal slices because masonry buttresses are typically built in horizontal courses.

According to simple elastic theory, when the axial thrust falls outside the middle third of the rectangular section, a stress-free zone will develop. This surface is illustrated by the dotted line, defined by the condition $m p=3 n m$, derived from the assumption that the compressive stress distribution is linear in the fractured region. Because of the unilateral character of masonry, a region will separate from the rest of the buttress and modify the conditions of equilibrium. Obviously, the collapse load $F$ will be less than the overturning load for the solid buttress $F_{s}$. As a result of 

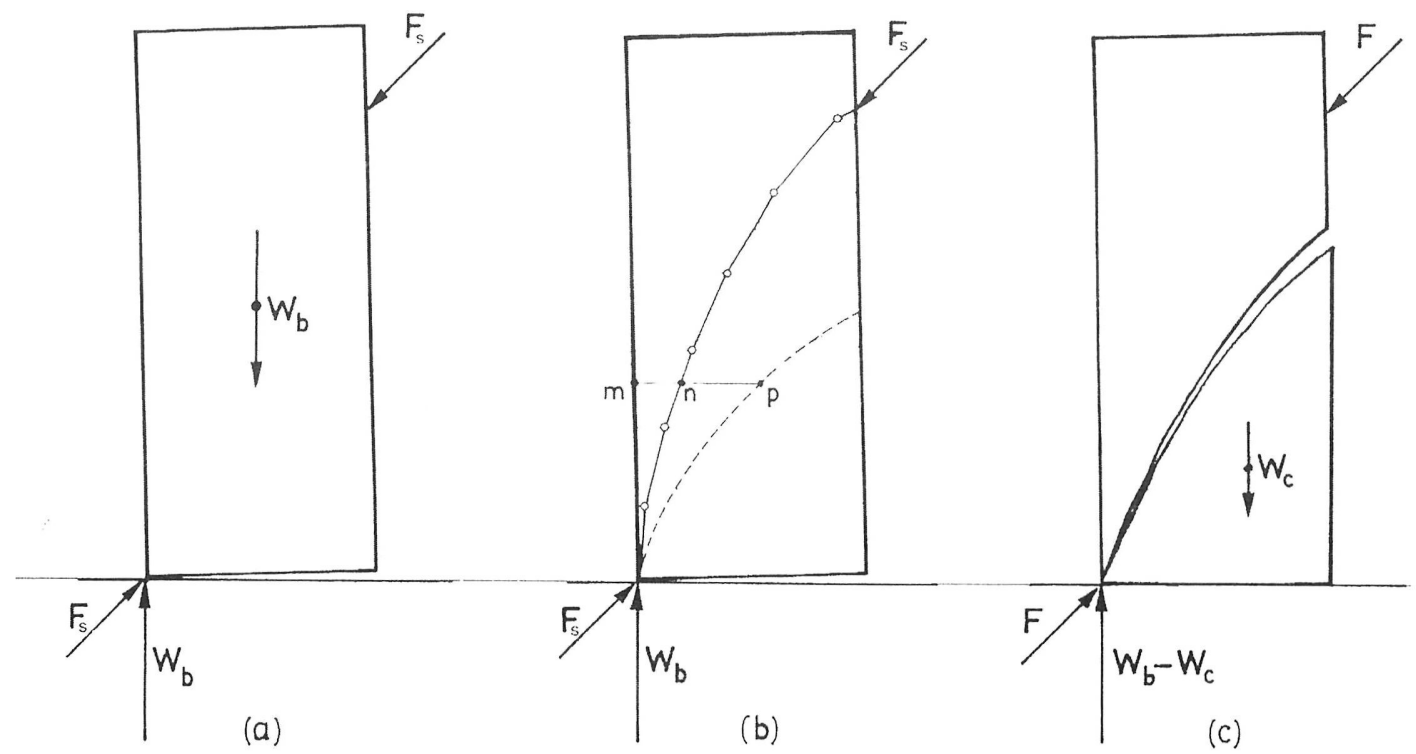

Fig. 1. Collapse of a masonry buttress (a) monolithic buttress; (b) buttress formed by horizontal courses of masonry, showing the line of thrust; and (c) separation of the buttress at collapse

the change in the equilibrium conditions, the form of the surface of fracture changes. The following analysis defines this surface and presents a method to calculate the corresponding collapse load. The study will be restricted to isolated buttresses resisting concentrated loads, as is common for Gothic buttresses. The general approach can also be applied to retaining walls, dams; or towers subjected to distributed loads (earth, water, or wind pressure). The method is applicable to any material with moderate compressive strength and low tensile strength, such as stone, brick, rubble, adobe, earth, or other traditional masonry construction materials.

\section{Brief Historical Outline}

The history of masonry buttress analysis and design has not been written, and a brief outline is provided here. Traditionally, historians of construction have considered buttresses to be a subject of secondary interest, and the information is widely dispersed. The following outline is restricted to the problem in question: the overturning collapse of a buttress and the formation of a surface of fracture. Le Creulx (1774) makes the first mention of the collapse state of buttresses in his investigation of the thrust of arches in a model bridge. Another French engineer, Gauthey, made the first published mention of the problem in relation to bridge collapse: "La chûte d'un pont ne porrait guére arriver sans qu'il ne se fit quelques disjonctions dans ses culées" ("The collapse of a bridge could hardly occur without some disjunction of the abutments") (Gauthey 1809). However, Gauthey did not publish any calculations to support this claim. It is known that Gauthey made collapse tests on arches, and he may have observed the fracture of the buttress from his own tests or from the tests by Le Creulx. While editing the works of Gauthey, Navier became interested in this observation and found experimental confirmation of the buttress fracture in a test by Mayniel. Mayniel wrote, "Un mur de 20 pieds de hauteur, dont on avait laissé consolider la maçonnerie, s'est rompu au nivel du sol, en formant une ligne de rupture qui eût pu, dans le profil, être la diagonale dún carré quie eût eu pour côté l'épaisseur du mur." ("A wall 20 feet high, made of consoli- dated masonry, broke at the ground level, in forming a line of rupture that passes across the profile as the diagonal of a square with the width of the thickness of the wall") (Mayniel 1808). Hence, the surface of fracture was observed to form at an angle of $45^{\circ}$. There is no drawing of the test result, but the description is similar to a test reported by Burgoyne (1853) and studied by Harkness et al. (2000) (Fig. 2).

In his review of Gauthey's work, Navier made some calculations in an appendix to examine the angle of fracture and justify

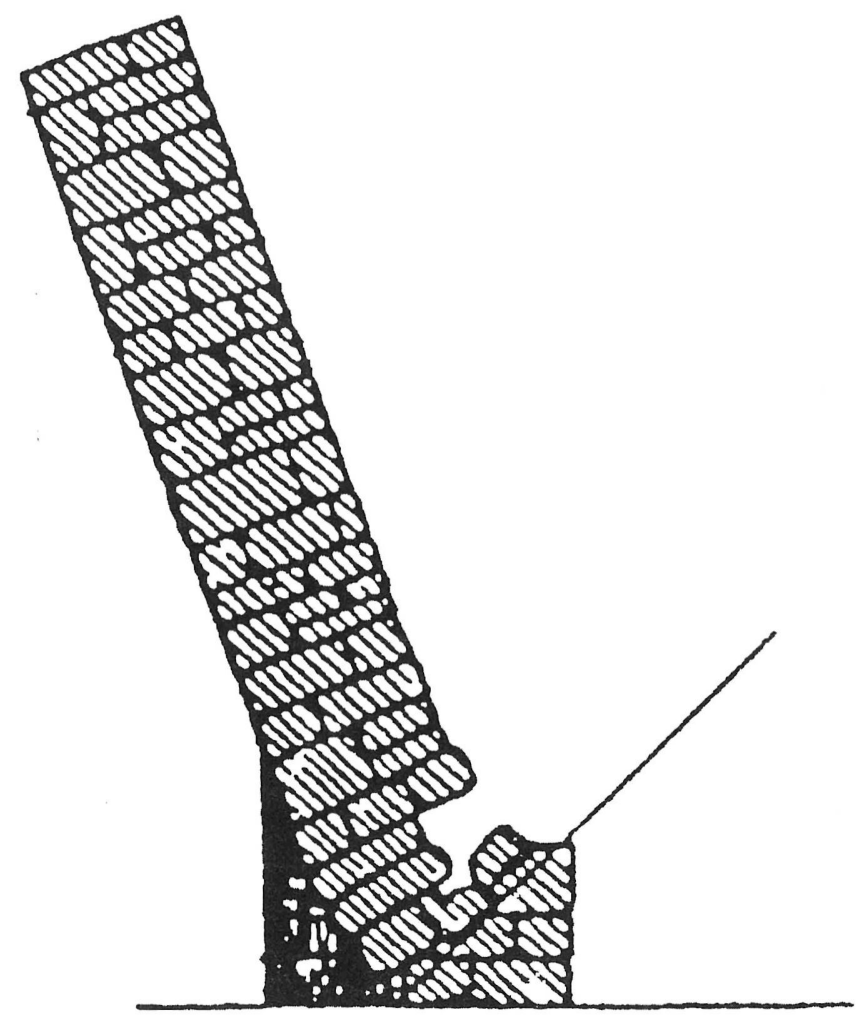

Fig. 2. Collapse tests on retaining walls made by Burgoyne (1853) 


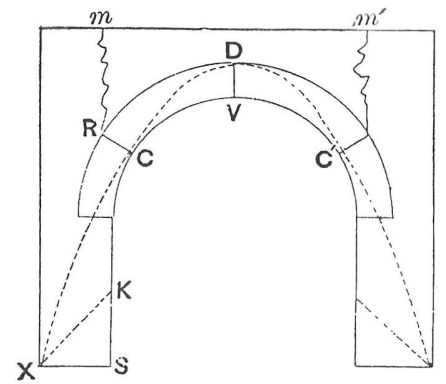

Fig. 3. Collapse of a vault supported on masonry buttresses (Cain 1879)

the value of $45^{\circ}$ (Gauthey 1809). Navier made similar comments in his edition of Bélidor's La Science des ingénieurs Bélidor (1813), but he was not entirely satisfied. In later editions of Gauthey's works (1832 and 1843), Navier investigated the problem again. He also included the topic in the second edition of his Resumé des leçons (1839). In every case, Navier assumed, without justification, that the fracture was a plane, and he employed Coulomb's approach of maxima and minima to obtain the angle of the plane at the collapse state.

An obscure Spanish engineer of the beginning of the 19th century, Monasterio, (unpublished manuscript-circa 1800) studied this problem independently. Monasterio considered a structure of rigid blocks and dedicated a chapter of his unpublished manuscript on vault theory to the collapse of buttresses. Following Navier's publications, several French engineers also studied the problem, including Audoy (1820), Persy (1834), and Dupuit (1870). In addition, Seguin (1826) and Vicat (1832) experimented on the strength of masonry buttresses to resist the pull of the main cables of suspension bridges. In both cases a plane fracture was observed, which Navier (1839) interpreted as proof of the correctness of his approach. In Germany, Walther (1855) analyzed the problem briefly. In the United States, Haupt (1851) and Cain (1879), both following Gauthey's observations, commented on the necessity of taking into account the loss of resistance caused by the fracture of the buttress. Fig. 3, from Cain based on Haupt, postulates a fracture in the buttress along line $X K$. An approximate line of thrust has been drawn, showing its relationship with the assumed fracture (Cain 1879).

The historical thread of the idea appears to finish here. After more than a century, Heyman (1992) investigated the formation of fracture surfaces in leaning walls and towers. Heyman's work and recent studies on the safety of buttresses (Huerta and López 1997) suggested the necessity for the present study. Independently, recent studies of the collapse of rigid block walls under seismic action have observed a surface of fracture (Carocci 2001). In addition, Baggio and Trovalusci (1995) used a rigid-block approach to study simple leaning walls and to ascertain the influence of the type of bonding in the strength of buttresses. The fracture was observed in full-scale tests of masonry structures by Pinto et al. (2001) and in model tests by Ochsendorf (2002). These experiments have illustrated the need for a general theory to predict the load capacity of masonry buttresses.

\section{Rectangular Buttress: Proof of Straight Fracture}

This paper aims to determine the shape of the fracture and the corresponding value of load necessary to overturn a masonry buttress subjected to concentrated loads. The study begins with the

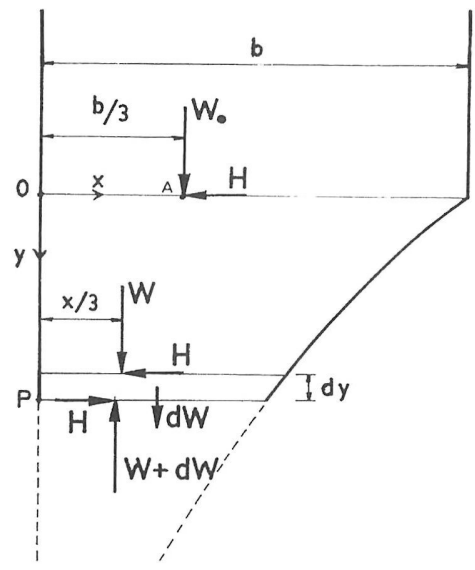

Fig. 4. Equilibrium of fractured region

simple case of a buttress of uniform rectangular section. To determine the shape of the fracture at overturning, it is necessary to assume a compressive stress distribution in the fractured region of the masonry. It is reasonable to assume a linear stress distribution, with a fracture occurring at the location of zero compressive stress, according to simple elastic theory. This leads to the middle-third rule: for a rectangular cross section, tension will occur when the normal force falls outside of the middle third of the cross section. Heyman (1992) and other authors (La Mendola and Papia 1993) have used the same approach.

This assumption leads to an unexpected and simple result. In a rectangular region of a buttress, the surface of fracture that defines the zero stress limit is straight, rather than curved as assumed in Fig. 1(c). (In actual buttresses with a constant throughthickness, the surface of fracture is planar.) Thus at the failure state, the lower portion of the buttress is a triangular wedge supporting an uncracked, upper portion of the buttress, with force resultants acting at the one-third point of the lower portion.

Initial iterative calculations revealed the formation of a straight fracture, although it was unexpected. The error function involved in Heyman's (1992) solution for leaning towers and walls suggested a similar complex function or no exact solution to the problem. However, the results of several computer analyses on rectangular buttresses of different forms with different concentrated loads, all give the same result: a straight fracture. Theoretical work followed, and the following simple mathematical proof was developed in collaboration with J. Heyman (personal communication, March 13, 2001).

In Fig. 4, a rectangular portion of a buttress supports an inclined load with horizontal component $H$. In the rectangular region, the line of thrust is easily calculated by considering horizontal slices of masonry (the problem is statically determinate), and it has the form of a rectangular hyperbola (Rankine 1864). The thrust approaches the outer limit, and, at a certain height, the line of thrust will touch the limit of the middle third. This is the origin of the surface of fracture. Below this level, some of the masonry will separate from the buttress, and the conditions of equilibrium must be recalculated. The form of the line of thrust will change, and, at Point A, a discontinuity in the curvature of the line will appear. As explained previously, in the cracked region there is a direct relationship between the line of thrust and the curve of fracture [Fig. 1(b)].

To determine the shape of the fracture, the equilibrium of a horizontal slice in the lower cracked portion is examined. Assuming that vertical forces act at one-third of the width (the kern point 
for a rectangular section), a thin horizontal slice of masonry is analyzed, (Fig. 4). The slice has a thickness $d y$ and is subjected to a constant horizontal force $H$ and a varying vertical force from above $W$. Because the problem is regarded as two-dimensional, it is convenient to define a density per unit area of the elevation $\gamma$, which accounts for the depth (through-thickness) of the buttress and the density of the material.

Enforcing moment equilibrium for the horizontal slice of width $x$ about Point $P$

$$
\frac{W x}{3}+\frac{x d W}{2}=\frac{W x}{3}+d\left(\frac{W x}{3}\right)+H d y
$$

Simplifying and solving for $W$ gives

$$
W=\frac{x}{2}\left(\frac{d W}{d x}\right)-3 H\left(\frac{d y}{d x}\right)
$$

but

$$
d W=\gamma x d y
$$

Combining Eqs. (2) and (3) gives

$$
W=\frac{\gamma x^{2}}{2}\left(\frac{d y}{d x}\right)-3 H\left(\frac{d y}{d x}\right)
$$

Differentiating Eq. (4) with respect to $x$ and combining with Eq. (3) gives

$$
\frac{d W}{d x} \equiv \gamma x \frac{d y}{d x}=\gamma x \frac{d y}{d x}+\frac{\gamma x^{2}}{2}\left(\frac{d^{2} y}{d x^{2}}\right)-3 H\left(\frac{d^{2} y}{d x^{2}}\right)
$$

which reduces to

$$
\left(\frac{\gamma x^{2}}{6}-H\right)\left(\frac{d^{2} y}{d x^{2}}\right)=0
$$

To satisfy Eq. (6)

$$
\left(\frac{d^{2} y}{d x^{2}}\right)=0
$$

It follows that $d y / d x$ is constant, and the curve of the fracture must be a straight line. Eq. (6) is also satisfied by the condition

$$
H=\frac{\gamma x^{2}}{6}
$$

where $H$ is known, and $x$ is constant, i.e., the fracture is a vertical line. This particular solution corresponds to the case where the line of thrust is also a vertical line, which occurs when a rectangular buttress is subject to the action of a horizontal load at the top, with horizontal plane joints (Dupuit 1870; Milankovitch 1910; Huerta 1990; Harvey 1991).

In summary, a masonry buttress at the limit of overturning will form a planar fracture at the base. The fracture can be assumed to be linear in a region that is rectangular in both elevation and cross section. In a real buttress, the fracture line will not be perfectly straight and will be influenced by the composition of the masonry. In addition, the exact stress state is unknowable and will not be precisely linear as assumed. However, this is the simplest and most reasonable assumption, and it provides insight into the response of buttresses to lateral loads.

\section{Progression of Cracking until Collapse}

A rectangular buttress is subjected to the action of an inclined force divided into its vertical and horizontal components $V$ and

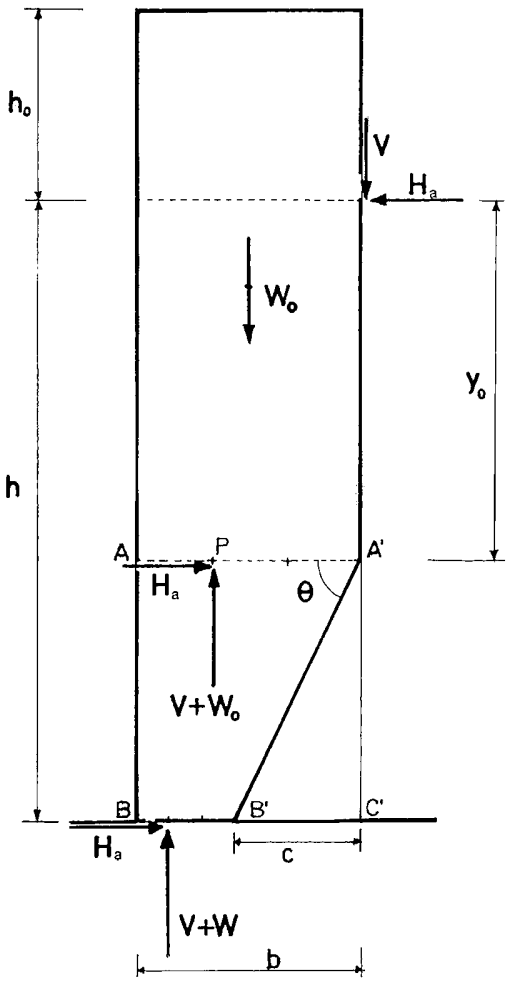

Fig. 5. Rectangular buttress with concentrated loads

$H_{a}$ (Fig. 5). For a particular value of this force, the thrust will pass through the outer middle third at a distance $y_{0}$ below the application of the force. At this height, a crack will just form on the inner face and spread downward. The value of the force can be determined in the following steps, and the progression of cracking as the load is increased can be postulated. The weight of the upper region of the buttress is

$$
W_{0}=b \gamma\left(h_{0}+y_{0}\right)
$$

and taking moments with respect to $P$

$$
W_{0}\left(\frac{b}{6}\right)+V\left(\frac{2 b}{3}\right)=H_{a} y_{0}
$$

Now, Eq. (4) allows for the calculation of the inclination of the line of fracture. Setting $H=H_{a}, x=b$ and $W=W_{0}$ gives

$$
\frac{d y}{d x}=\tan \theta=\frac{W_{0}}{3\left(\frac{\gamma b^{2}}{6}-H_{a}\right)}
$$

where $\theta=$ angle of the line of fracture with the horizontal. At the base, the area B-B' supports the entire buttress (Fig. 5). The prismatic wedge $\mathrm{A}^{\prime} \mathrm{B}^{\prime} \mathrm{C}^{\prime}$ is separated from the buttress, rests on the ground, and does not contribute in any way to resisting the overturning moment of the external load.

The situation in Fig. 5 occurs between the uncracked state and the collapse state. The buttress has fractured, but it is still capable of resisting the external force. As the applied horizontal force $H_{a}$ increases, the plane $\mathrm{A}-\mathrm{A}^{\prime}$ moves upward, and new values of the angle of fracture $\theta$ are obtained. When the fracture reaches the outside edge at the base, the buttress will be on the point of collapse. This occurs when

$$
\theta=\tan ^{-1}\left(\frac{h-y_{0}}{b}\right)
$$




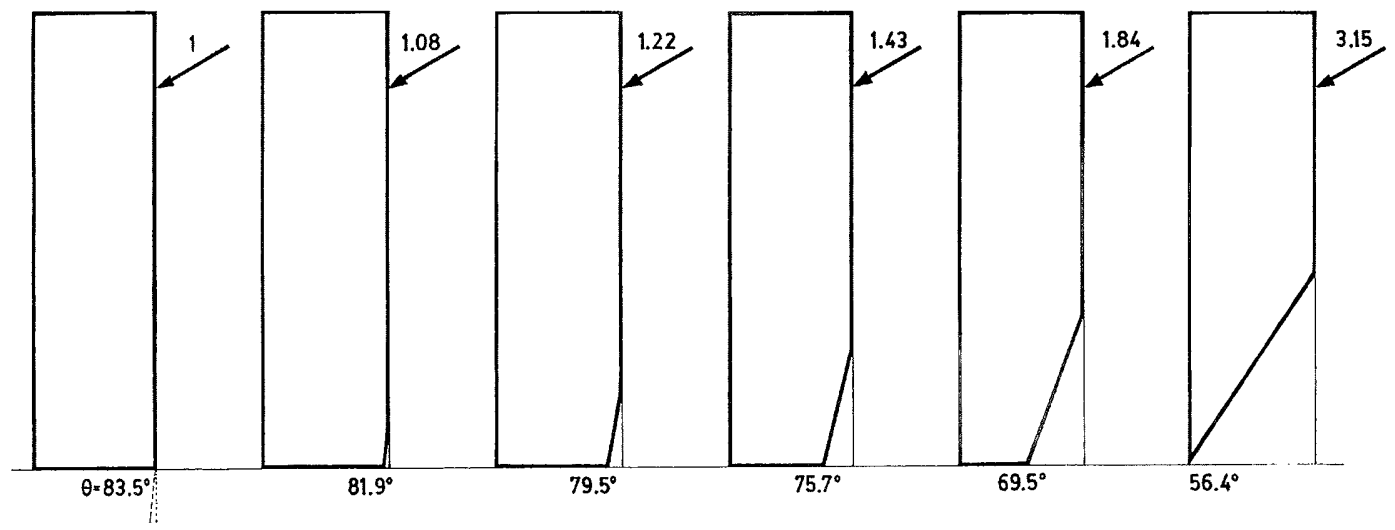

Fig. 6. Progression of cracking until collapse

Therefore, a very simple algorithm can be used to follow the evolution of the crack until collapse. This process is shown in Fig. 6 for $h_{0}=h / 5 ; h / b=3$, and the force inclined at $30^{\circ}$. The magnitude of the force that will just initiate the crack at the base is taken as unity $\left(F_{c r}=1.0\right)$. The fracture has been calculated at height intervals of $h / 10$. In this case, the collapse occurs at approximately $y_{0}=h / 2$. The value of the collapse load $(F=3.15)$ may be compared with the value obtained for the solid buttress $\left(F_{s}=4.37\right)$. In this example, the fracture reduces the resistance of the buttress to overturning by $28 \%$. The reduction in resistance varies depending on the geometry of the buttress and the location and inclination of the force, but this result justifies the present study. The common assumption of monolithic buttresses is clearly unsafe.

The inclination of the line of fracture changes as it grows, from nearly vertical at the state of initial cracking to the minimum angle $\theta$ at the collapse state. The process of formation and transmission of the crack in an actual buttress is illustrated in Fig. 7. The movement of the fracture through the masonry is similar to the progressive leaning of a wall or tower. As Heyman (1992) explained, an increase in the applied load "will transfer some of

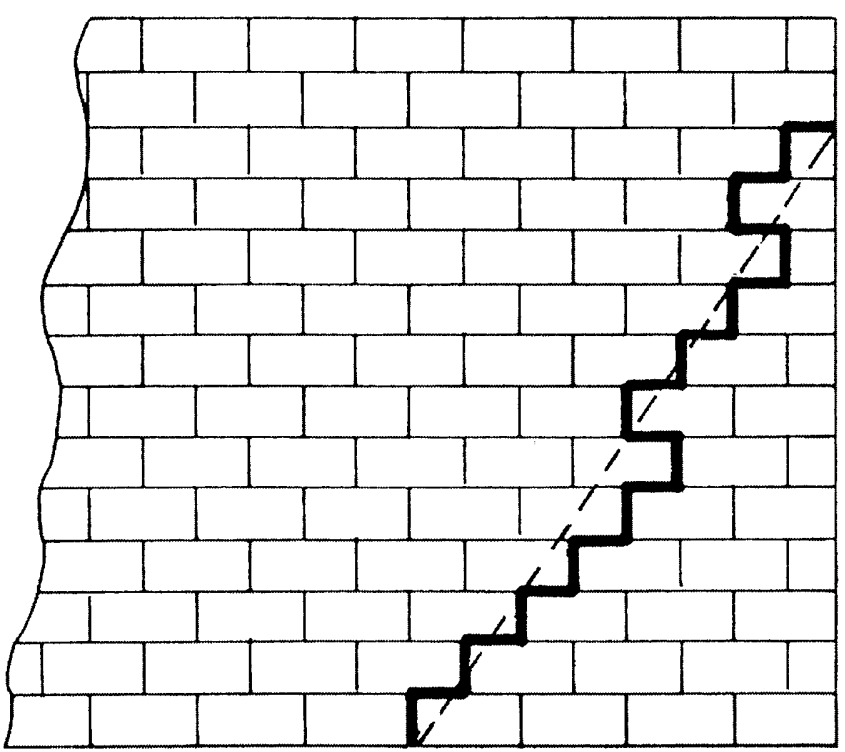

Fig. 7. Schematic illustration of an "actual" fracture, after Heyman (1992) the 'bricks' just above the fissure to the passive pile just below, where they can play no further part in contributing to the stability of the masonry."

\section{Equations of Equilibrium at Collapse}

The preceding paragraphs presented a method to obtain the collapse load for a masonry buttress by successive calculation. When the fracture at collapse is planar, that is, it is entirely within a prismatic zone, some general formulas may be derived. Fig. 8 presents a typical Gothic buttress and the associated variables.

Assuming that the buttress is not fractured, the weight of the buttress and the vertical component of the applied load $V$ act to stabilize the buttress. The stabilizing moment for the buttress is

$$
M_{s}=W_{b} x_{b}+V b
$$

where $x_{b}$ is the horizontal centroid of the buttress measured from the hinge of overturning. Applying moment equilibrium to Fig. 8(b)
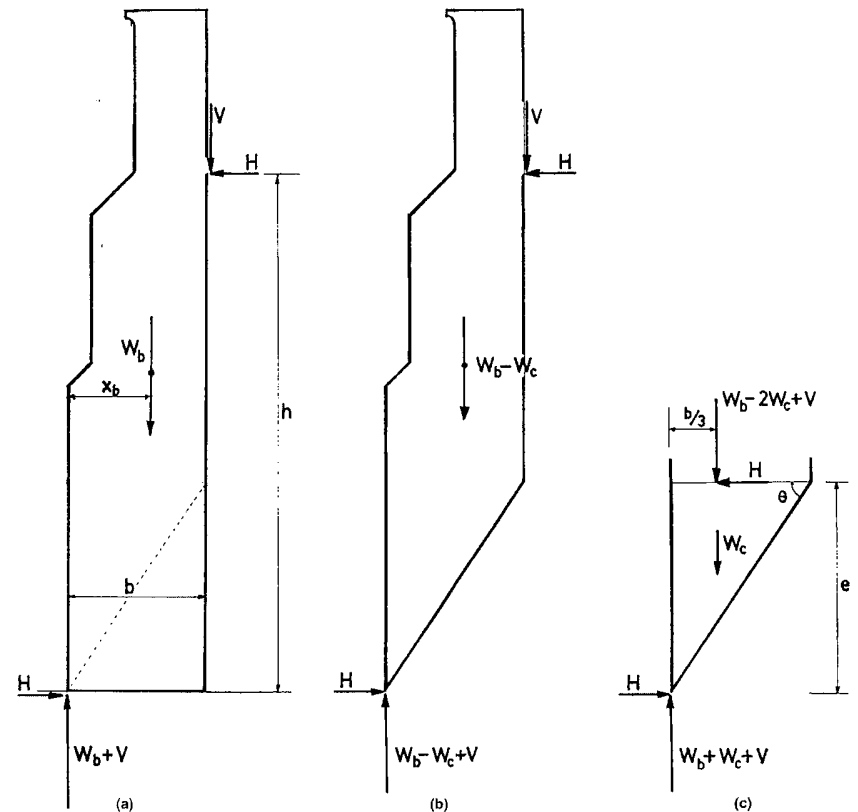

(c)

Fig. 8. Equilibrium of a fractured buttress at collapse 


$$
M_{s}-W_{c}\left(\frac{2 b}{3}\right)-H h=0
$$

where the stabilizing moment is reduced by the loss of the ineffective cracked region of the buttress, which weighs

$$
W_{c}=\frac{b e \gamma}{2}
$$

Substituting the values of $M_{s}$ and $W_{c}$ gives

$$
W_{b} x_{b}+V b-\frac{b^{2} e \gamma}{3}-H h=0
$$

Eq. (16) is the general linear equation for the force that will overturn a buttress of the form illustrated in Fig. 8(b), with a fracture at height $e$. There are two unknowns: the collapse load and the critical fracture height $e$. To solve for the two unknowns, an additional equation is obtained by examining the internal equilibrium of the buttress in the lower, cracked region, as shown in Fig. 8(c). (The unknown force at collapse $F$ may be resolved into components $V$ and $H$. Alternatively, $V$ may be considered to be constant with $H$ as the unknown.)

The triangular wedge is loaded by the force resultants from the upper region of the buttress, applied at one-third of the width of the buttress, in order to initiate the propagation of the fracture at height $e$. The weight of the fractured wedge $W_{c}$ also acts at the one-third point. Applying moment equilibrium to Fig. 8(c) gives

$$
\left(W_{b}-W_{c}+V\right)(b / 3)-H e=0
$$

which becomes

$$
W_{b} b-\frac{b^{2} e \gamma}{2}+V b-3 \ddot{H} e=0
$$

Combining Eqs. (16) and (18) to eliminate $e$ results in a quadratic equation that gives the value of the collapse load. In general, there are two unknowns: the height of the fracture $e$ and the value of the collapse load $H$. Eqs. (16) and (18) provide two equations to solve for these two unknowns. The previous equations can be adapted to account for buttresses with varying profiles and more complex lateral loading, such as horizontal overturning forces at two different heights (perhaps as a result of two flying buttresses in the case of tall Gothic buttresses). The solution is valid provided that (1) the lower, fractured region of the buttress is rectangular in elevation, with constant depth-density; (2) there are no external loads applied to the lower, fractured region of the buttress; and (3) sliding does not occur. Finally, the yield condition (the intact masonry exists in a state of axial compression) must be checked throughout the buttress. The line of thrust must be contained everywhere within the masonry. It is possible that another mechanism exists with a lower value of the load for a hinge located in a higher region of the buttress. The analyst must verify that an upper part of the buttress will not give way before reaching the calculated value for the whole buttress. In addition, the analyst must check for sliding failure in the buttress to ensure that overturning failure is the governing mechanism of collapse.

\section{Limits on Sliding}

Although overturning failure will determine the stability for most masonry buttresses, failure by sliding is also possible. Sliding will be most critical at the height of the applied force, and the vertical forces must develop sufficient friction to overcome this possibility. To avoid sliding

$$
H<(W+V) f_{s}
$$

where $W=$ weight of the buttress above the level being considered; $V=$ vertical component of the applied force; and $f_{s}=$ assumed static coefficient of friction. Typical values of $f_{s}$ are $0.6-0.7$ for stone on stone (Rankine 1863). Sliding is most likely to occur for an applied force near the top of the buttress, where the weight of the buttress above is minimal. The use of pinnacles on some Gothic buttresses can play an important role to prevent sliding in this instance (Heyman 1968). Although it is unlikely to occur in practice, a horizontal applied load near the base of a buttress will also lead to sliding failure rather than overturning failure.

\section{Rectangular Buttresses}

The methods described previously can be applied to the specific case of a rectangular buttress. The horizontal force component is assumed to increase until the collapse state, while the vertical component $V$ remains constant. This situation occurs in the event of leaning buttresses, in which the arch thrust increases as a result of large deformations, but the vertical load from the arch remains constant (Ochsendorf 2002).

In this case, the weight of the buttress is

$$
W_{b}=b h_{b} \lambda
$$

where $h_{b}$ is the total height of the rectangular buttress. The horizontal centroid is simply

$$
x_{b}=\frac{b}{2}
$$

Thus Eq. (16) governing the rotational equilibrium of the buttress is now

$$
H=\left(\frac{b}{h}\right)\left(\frac{h_{b} b \gamma}{2}+V-\frac{b e \gamma}{3}\right)
$$

Eq. (18), again solving for $H$, becomes

$$
H=b\left(\frac{h_{b} b \gamma+V}{3 e}-\frac{b \gamma}{6}\right)
$$

Three dimensionless factors for rectangular buttresses simplify the problem

$$
\xi=\frac{e}{h}
$$

relating the fracture height to the height of the applied force

$$
\mu=\frac{h}{h_{b}}
$$

relating the height of the applied force to the total height of the buttress and

$$
\psi=\frac{V}{b h_{b} \gamma}
$$

relating the vertical load to the weight of the buttress.

Substituting these factors, Eq. (22) becomes

$$
H=b^{2} \gamma\left(\frac{1+2 \psi}{2 \mu}-\frac{\xi}{3}\right)
$$

and Eq. (23) becomes

$$
H=b^{2} \gamma\left(\frac{1+\psi}{3 \mu \xi}-\frac{1}{6}\right)
$$


From Eqs. (27) and (28), the critical values of $H$ and $\xi$ can be determined. Combining Eqs. (27) and (28) to eliminate $H$ produces the following quadratic equation for the fracture height

$$
\xi^{2}-\left(\frac{1}{2}+\frac{3}{2 \mu}+\frac{3 \psi}{\mu}\right) \xi+\left(\frac{\psi+1}{\mu}\right)=0
$$

Solving Eq. (29) for $\xi$ gives the location of fracture height leading to failure in a rectangular buttress. (The correct root must be between 0 and 1.) This value can then be substituted into Eq. (27) or Eq. (28) to find the critical failure load. From Eqs. (27) and (28) it is clear that the resistance to overturning is proportional to the square of the thickness $b$, to the specific weight of the masonry, and to a certain dimensional function. This function depends on the form of the buttress (in this case assumed rectangular), the height of the horizontal load, and the relative value of $V$ with respect to the total weight of the buttress.

As an example, a rectangular masonry buttress with a height of $13.5 \mathrm{~m}$ and a horizontal force applied at a height of $10 \mathrm{~m}(\mu$ $=0.74$ ) is considered. The depth of the buttress is uniform and equal to $1.5 \mathrm{~m}$, and, with a material density of $20 \mathrm{kN} / \mathrm{m}^{3}$, the depth-density $\gamma$ becomes $30 \mathrm{kN} / \mathrm{m}^{2}$. The width of the buttress at the base $b$ is $3.5 \mathrm{~m}$. The buttress supports a vertical load $V$ of 100 $\mathrm{kN}$, so the vertical load is approximately $7 \%$ of the buttress weight $W_{b}$ of $1,420 \mathrm{kN}(\psi=0.07)$. Solving Eq. (29) for these values gives $\xi=0.68$, which corresponds to a fracture height of $e=6.8 \mathrm{~m}$, and the collapse value of $H$ is $200 \mathrm{kN}$. This may be compared with the theoretical overturning load of $283 \mathrm{kN}$ for the solid buttress. In this example, the fracture reduces the strength of the buttress by approximately $30 \%$. From Eq. (19), the sliding limit occurs at a horizontal load of $327 \mathrm{kN}$ for $f_{s}=0.7$, verifying that failure by overturning governs the colläpse.

The results will be very different for an applied force with $V$ and $H$ increasing proportionally, because the component $V$ has a stabilizing effect. For example, in the above case, if $V=H$, corresponding to an external thrust inclined at $45^{\circ}$ with the horizontal, Eqs. (22) and (23) give a collapse value of $V=H=252 \mathrm{kN}$ for the fractured buttress, as compared to the overturning load of $V$ $=H=382 \mathrm{kN}$ for the solid buttress.

\section{Safety of Buttresses}

Buttress design and analysis has been considered historically as a subject of secondary interest, and the primary problem was to obtain the thrust of the vault. Once the thrust was known, the buttress system was considered to be rigid and monolithic, and it was a matter of simple statics to know if the buttress would collapse by overturning. (Some builders also checked for the possibility of sliding.) Throughout history and at present, the real problem is how to measure safety, whether in design or assessment. Bélidor (1729) was the first to attempt this problem by simplifying La Hire's theory (La Hire 1712) to more easily obtain the vault thrust. The depth of the buttress was then calculated so that the stabilizing and overturning moments would be equal. This meant that the resistance of the buttress exactly equaled the thrust of the vault, leaving the structure on the point of collapse. Aware of this danger, Bélidor suggested adding several centimeters to the calculated depth of the buttress. It is doubtful that such an increase would guarantee the safety of a buttress several meters wide, particularly in light of the possibility of a fracture at the collapse state. However, La Hire's theory was incorrect, but its application leads to greater and more inclined thrusts, which ensured the safety of the buttress. Therefore, buttresses designed
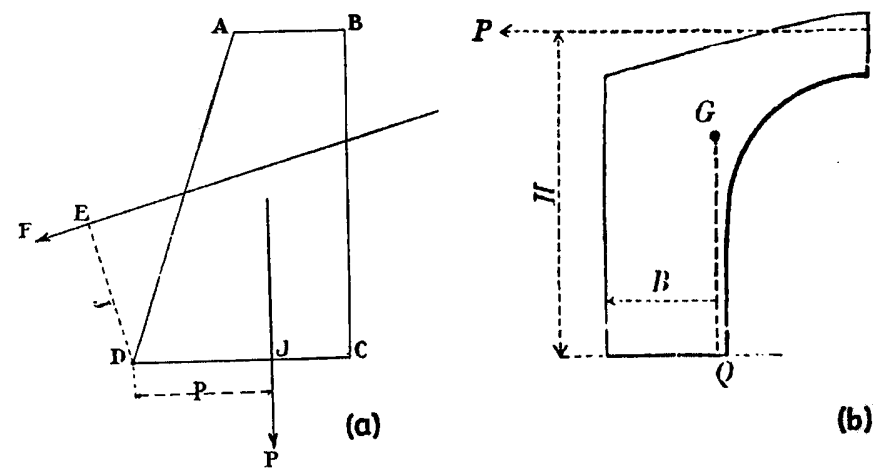

(b)

Fig. 9. Buttress stability: (a) applied force is increased (Aragon 1909); (b) horizontal component is increased (Croizette-Desnoyers 1885)

with La Hire's method were satisfactory in comparison to existing buttresses and the traditional geometrical design rules.

When Audoy (1820) calculated the buttresses with the correct thrust following the vault theory of Coulomb (1773), he obtained overly slender buttress designs. It was necessary to increase the buttress depth in some way, and Audoy suggested multiplying the horizontal thrust by a certain factor, the "coefficient de stabilité." The problem was to determine the value of this coefficient. Audoy decided that La Hire's theory had functioned correctly for 100 years and calculated the factor so that the depth of the buttress would be the same as that obtained from the (incorrect) theory of La Hire. The so-called "stabilité de La Hire" was a reference for the first half of the 19th century in France (Huerta and Hernando 1998). Audoy obtained a coefficient of 1.9 , often rounded to 2 , which appeared in many French engineering manuals of the 19th and early 20 th centuries.

The matter may appear evident to a modern engineer or architect, but some misunderstanding and ambiguity continues to pervade the different ways to define the stability coefficient. With reference to Fig. 9(a) from Aragon (1909), force $F$ will be multiplied by the stability coefficient $c$, and the buttress will be designed so that $(c F)(\mathrm{ED})=(\mathrm{DJ})(P)$. In this assumption, the thrust grows until it reaches a collapse value. This appears initially to be the same as Audoy's approach, but it is not. Fig. 9(b) from Croizette-Desnoyers (1885) may be used to illustrate the difference. The thrust at the crown of the half-vault $P$ multiplied by the stability coefficient $c$ must be in equilibrium with the stabilizing moment of the mass. Taking moments with respect to the external border of the buttress, with the total weight $Q$ of the vault plus the buttress, gives $(c P)(H)=(B)(Q)$. The crucial difference is that in the first case the stabilizing vertical component of the thrust grows; while in the second case only the destabilizing horizontal component grows. The results may vary considerably, as illustrated in the previous example of the rectangular buttress. However, the method of the "coefficient de stabilite" measures the safety in an indirect way. The problem of the safety in any masonry structure, whether an arch or a buttress, is that the possibility exists for a line of thrust to lie within the masonry. For buttresses, the thrust should not approach the edge of the masonry; if the thrust touches the border, a hinge will form and the buttress will collapse by overturning. It is a matter of geometry, and the use of adequate stability coefficients ensures that sufficient separation exists between the thrust and the edge of the masonry.

Moseley (1843) was the first to estimate the safety of a buttress by limiting the distance of the thrust from the edge of the 

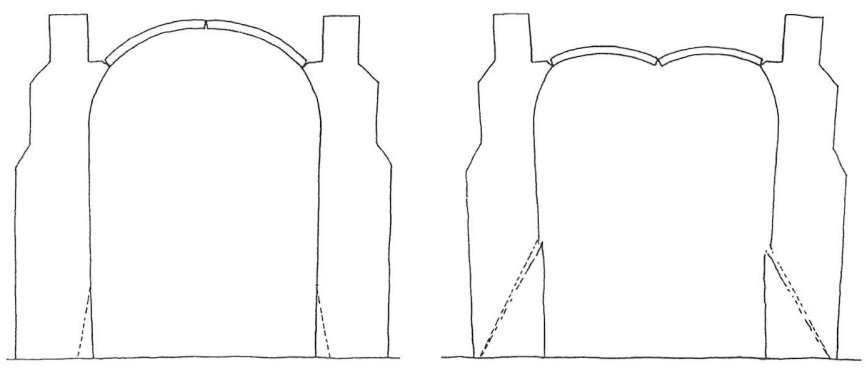

Fig. 10. Collapse of a barrel vault by buttress leaning (after Huerta et al. 1997)

buttress. He called this distance the modulus of stability, but provided no values for this modulus, leaving implicitly the question to the judgement of the engineer or architect. Rankine (1863) expanded Moseley's idea and proposed a stability of position, obtained by limiting the deviation of the thrust from the center of the diameter. This distance $q$ was defined as a fraction of the diameter. Interestingly, Rankine gives different values of $q$ depending on the type of structure. For the buttresses of buildings he recommended $1 / 6$, so the force reaction arrived at the middle third near the base of the buttress. For other type of buttress systems like retaining walls, Rankine admitted much greater values of $3 / 8$ or $3 / 10$. For a rectangular buttress, the value of $1 / 6$ will prevent the appearance of tension in the section, but this did not concern Rankine because he allowed some cracking in other masonry structures. The slender Gothic buttresses may have even more restrictive values. For example, in the case of Gerona cathedral, the value of $q$ is less than $1 / 8$, meaning that the thrust at the base of the buttress falls within the central quarter (Huerta 1998).

Another way to measure the location of the thrust is to divide the diameter by two times the deviation of the force from the center. The figure obtained may be compared with the geometrical factor of safety defined by Heyman $(1969,1982)$ for masonry arches. While Heyman's coefficient refers to the entire structure, local sections must be checked for buttresses. The geometrical coefficients for buttresses are typically 3 or greater ( 4 in the case of Gerona), which can be compared with a typical geometrical coefficient of safety of 2 for arches. This method can be used to determine the center of thrust precisely at the critical section of the buttress and to accurately estimate geometrical safety. As mentioned previously, the critical failure will often occur at the base of the buttress, but this is not always true, particularly in the case of stepped buttresses.

The reason for the greater safety coefficient lies not so much in the safety of the buttress but rather in the safety of the vault. An eccentric thrust at the base of the buttress will tend to produce differential settlements resulting in some leaning. A leaning of $1^{\circ}$ will not immediately threaten the rectangular buttress studied previously. But at the springing of the vaults $10 \mathrm{~m}$ above, this small lean will cause a spreading of $0.17 \mathrm{~m}$ on each side and a total span increase of $0.34 \mathrm{~m}$. This will produce gross deformations in the vault, an increase in the thrust, more leaning, and possibly the collapse of the vault by snap-through (Huerta and López 1997; Huerta et al. 1997; Ochsendorf 2002) (Fig. 10). The collapse of leaning buttresses requires specific study and is discussed by Ochsendorf (2002).

\section{Bridge Collapse Analysis}

A final example will stress the importance of considering the fracture of the buttress. In masonry bridges, the collapse load is

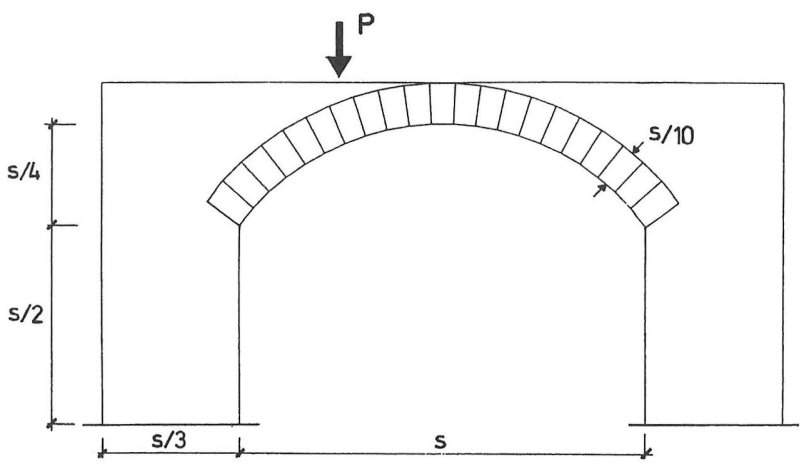

Fig. 11. Masonry bridge supporting a moving load

typically calculated considering the collapse of the arch vault (Heyman 1982). If the arch is relatively thick, lower values of the collapse load may be obtained by considering a collapse mechanism involving the abutment piers (Melbourne 1997). The value of the collapse load will be further reduced if the possibility of buttress fracture is considered. This case may be critical for some bridges.

The problem will be illustrated with reference to a simple example (Fig. 11). Three different analyses have been made: (1) collapse of the arch alone; (2) collapse of the arch plus monolithic abutments; and (3) collapse of the arch plus abutments, with the formation of a fracture in the abutments. The calculations have been made numerically, using linear programming methods as developed by Livesley (1978), computing the collapse load for every position of the moving load in each of the three cases. Fig. 12 presents the correct mechanisms for each case, and the results are summarized as influence lines in Fig. 13. The fracture of the

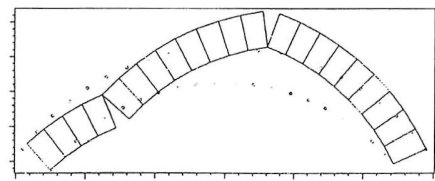

(a)

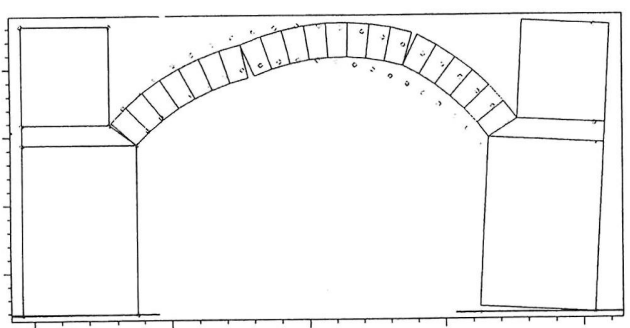

(b)

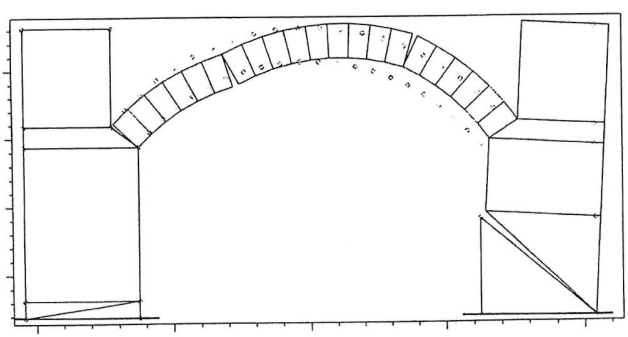

(c)

Fig. 12. Collapse mechanism: (a) arch; (b) arch on rigid abutments; and (c) arch on fractured abutments 


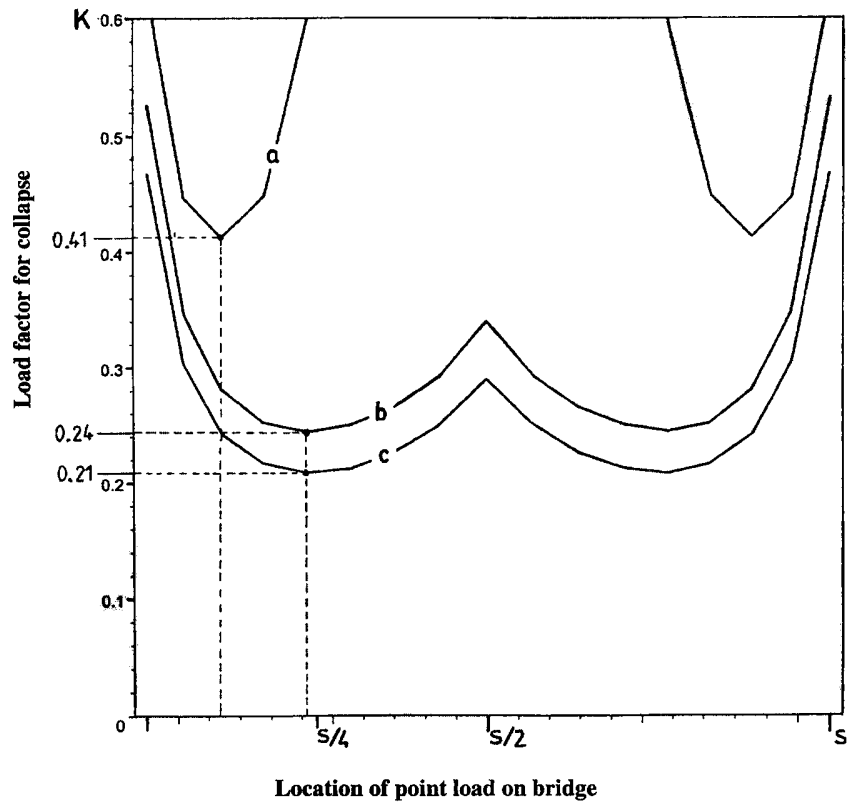

Fig. 13. Bridge collapse loads

abutments reduces the collapse load by approximately $14 \%$. A higher reduction of the collapse load would be obtained for a case with more slender abutments.

\section{Conclusions}

In summary

1. The overturning collapse of a masonry buttress involves the formation of a surface of fracture, which reduces the collapse load. Buttresses calculated on the basis of a monolithic assumption are unsafe.

2. The surface of fracture can be calculated by supposing that a crack forms when the internal line of forces falls outside the kern of the section (middle-third for rectangular cross sections). For a rectangular buttress the surface is a plane, allowing a simple calculation of the collapse load for most buttress forms. The problem is statically determinate for every supposed mechanism and involves the solution of a simple system of two equations with two unknowns.

3. In real buttresses, the fracture will depend on the composition of the masonry, and the planes of failure will occur along the existing joint surfaces. The method of straight-line fracture presented in this paper gives an approximate solution to the problem, which can be used to assess existing buttresses.

4. The recommended approach to quantify the safety of a buttress is to limit the position of the thrust within certain bounds, i.e., to use geometrical safety factors, analogous to those defined by Heyman for arches. Geometrical factors of safety are equivalent to the traditional geometrical rules of design used historically by master builders.

5. Detailed studies of the resistance of buttresses must include considerations for the lean of the buttress and interaction with other masonry components, such as intersecting cross walls.

6. In the study of the collapse of masonry arches, the fracture of the abutments should be considered. This can result in lower collapse loads for buttressed arches, such as those found in bridges or traditional building construction.

\section{Acknowledgments}

The writers wish to thank Professor J. Heyman and Professor C. R. Calladine for their helpful discussions and contributions to this paper. The first writer gratefully acknowledges the J. William Fulbright Foundation and the National Science Foundation for financial support.

\section{Notation}

The following symbols are used in this paper:

$b=$ width of buttress at base;

$c=$ stability coefficient multiplied by the overturning moment to provide safety;

$e=$ height of fracture from base of buttress;

$F=$ magnitude of applied force to overturn a fractured buttress;

$F_{c r}=$ magnitude of applied force to initiate the fracture in a buttress;

$F_{s}=$ magnitude of applied force to overturn a solid (unfractured) buttress;

$f_{s}=$ assumed static coefficient of friction for masonry;

$H=$ horizontal force causing failure of the buttress;

$H_{a:=}$ applied horizontal force;

$H_{c r}:=$ horizontal force at which cracking begins;

$H_{s}=$ horizontal force to overturn a solid (unfractured) buttress;

$h=$ height of applied force from base of buttress;

$h_{b}=$ total height of a rectangular buttress;

$M_{s}=$ stabilizing moment due to the weight of the buttress and the vertical force;

$q=$ buttress stability measure proposed by Rankine;

$V=$ applied vertical force;

$W=$ weight of the buttress above the section being considered;

$W_{b}=$ total weight of the buttress;

$W_{c}=$ mass of ineffective, fractured region of a buttress;

$W_{0}=$ weight of the unfractured, upper portion of the buttress;

$x_{b}=$ centroid of solid buttress measured from point of overturning;

$x, y=$ system of Cartesian space coordinates;

$\gamma=$ depth-density of buttress in units of $\mathrm{kN} / \mathrm{m}^{2}$;

$\theta=$ angle of inclination of the fracture measured from horizontal;

$\mu=$ coefficient of height at which the force is applied to a rectangular buttress;

$\xi=$ height of fracture divided by height of the applied force for rectangular buttress; and

$\psi=$ ratio of vertical load to the buttress weight for rectangular buttresses.

Aragon, E. (1909). Ponts et ouvrages en maçonnerie, Dunod, Paris (in French).

Audoy. (1820). "Mémoire sur la poussée des voûtes en berceau." Mémorial de l'officier du génie, 4, plates I-VI, 1-96 (in French). 
Baggio, C., and Trovalusci, P. (1995). "Stone assemblies under in-plane actions. Comparison between nonlinear discrete approaches." Computer methods in structural masonry, 3rd. Int. Symp., G. N. Pande and J. Middleton, eds., Swansea, U.K., 184-193.

Bélidor, B. F. (1729). La science des ingénieurs dans la conduite des travaux de fortification et architecture civile, Paris (in French).

Bélidor, B. F. (1813). La Science des ingénieurs dans la conduite des travaux de fortification et d'architecture civile,... Nouvelle édition avec des notes par M. Navier, F. Didot, Paris (in French).

Boothby, T. E. (1994). "Stability of masonry piers and arches including sliding." J. Eng. Mech., 120(2), 304-319.

Burgoyne, J. (1853). "Revetments or retaining walls." Corps Royal Eng. Papers, 3, London, 154-159.

Cain, W. M. (1879). Voussoir arches applied to stone bridges, tunnels, domes and groined arches, Van Nostrand, New York.

Carocci, C. F. (2001). "Guidelines for the safety and preservation of historical centres in seismic areas." Historical Constructions 2001, Proc., 3rd Int. Seminar Guimaraes, P. B. Lourenço and P. Roca, eds., Univ. do Minho, Portugal, 145-165.

Coulomb, C. A. (1773). "Essai sur une application des régles de maximis et minimis à quelques problémes de statique relatifs à l'architecture." Mémoires de mathématique et de physique, présentés à l'Académie Royale des Sciences par divers savants et lus dans ses assemblées, 7 , Paris, 343-382 (in French).

Croizette-Desnoyers, P. (1885). Cours de construction des ponts, Vve. Dunod, Paris (in French).

Dupuit. (1870). Traité de l'équilibre des voûtes et de la construction des ponts en maçonnerie, Dunod Editeur, Paris (in French).

Gauthey, E. M. (1809). Traité de la construction des ponts,... Publié par M. Navier, 2 vols, F. Didot, Paris (in French).

Gilbert, M., and Melbourne, C. (1994). "Rigid-block analysis of masonry structures." Struct. Eng., 72(21), 356-361.

Harkness, R. M., Powrie, W., Zhang, X., Brady, K. C., and O'Reilly, M. P. (2000). "Numerical modelling of full "scale tests on drystone masonry retaining walls." Geotechnique, 50(2), 165-179.

Harvey, W. J. (1991). "Stability, strength, elasticity, and thrustlines in masonry structures." Struct. Eng., 69(9), 181-184.

Haupt, H. (1853). General theory of bridge construction, Appleton, New York.

Heyman, J. (1966). "The stone skeleton." Int. J. Solids Struct., 2, 249279.

Heyman, J. (1968). "On the rubber vaults of the Middle Ages, and other matters." Gaz. des Beaux-Arts, 71, 177-188.

Heyman, J. (1969). "The safety of masonry arches." Int. J. Mech. Sci., $11,363-385$.

Heyman, J. (1982). The masonry arch, Ellis Horwood, Chichester, U.K.

Heyman, J. (1992). "Leaning towers." Meccanica, 27, 153-159.

Heyman, J. (1995). The stone skeleton. Structural engineering of masonry architecture, Cambridge University Press, New York.

Huerta, S. (1990). "Diseño estructural de arcos, bóvedas y cúpulas en España, ca. 1500-ca. 1800.” PhD thesis, Univ. Politécnica de Madrid, E.T.S. de Arquitectura, Madrid, Spain (in Spanish).

Huerta, S. (1998). "Mecánica de las bóvedas de la catedral de Gerona." Las grandes bóvedas hispanas, curso celebrado en Madrid 19-23 mayo de 1997, S. Tarragó, ed., CEDEX, Madrid, Spain, 53-65 (in Spanish).

Huerta, S. (1999). "The medieval 'scientia' of structures: The rules of Rodrigo Gil de Hontañón." Omaggio a Edoardo Benvenuto, Univ. of Genoa, Genoa, Italy, 29-30.

Huerta, S., and Hernando, R. (1998). "La teoría de bóvedas en el siglo XVIII: La contribución de Philippe de La Hire." Actas del Segundo
Congreso Nacional de Historia de la Construcción, Coruña, Instituto Juan de Herrera, CEHOPU, Univ. de la Coruña, Spain, 233-244 (in Spanish).

Huerta, S., and Lopez, G. (1997). "Stability and consolidation of an ashlar barrel vault with great deformations: The church of Guimarei." Structural studies, repairs, and maintenance of historical buildings, Sánchez and Brebbia, Eds., Computational Mechanics Publications, Southampton, U.K., 587-596.

Huerta, S., Rabasa, E., and Lopez, G. (1997). "Estudios estructurales previos a la restauración de la capilla del pazo de Antequeira en Rois." Technical Rep., Depto. de Estructuras de la ETSAM. Dirección Xeral do Patrimonio Cultural, Xunta de Galicia, Univ. Politécnica de Madrid, Madrid, Spain (in Spanish).

La Hire, P. (1712). "Sur la construction des voûtes dans les édifices." Mémoires de l'Académie Royale des Sciences de Paris, Paris, 70-78 (in French).

La Mendola, L., and Papia, M. (1993). "Stability of masonry piers under their own weight and eccentric load." J. Struct. Eng., 119(6), 16781693.

Le Creulx. (1774). Mémoire sur la nature de la poussée des voûtes... contre les culées, contnenant des expériences sur les effets qui en resultent, Library of l'École des Ponts et Chaussées, Paris (in French).

Livesley, R. K. (1978). "Limit analysis of structures formed from rigid blocks." Int. J. Numer. Methods Eng., 12, 1853-1871.

Mayniel. (1808). Traité expérimental, analytique et pratique de la poussée des terres et des murs de revêtement, D. Colas, Paris (in French).

Melbourne, C. (1997). "The collapse behaviour of multispan brickwork arch bridges." Struct. Eng., 75, 297-305.

Milankovitch, M. (1907). "Theorie der Druckkurven." Zeitschrift für Mathematik und Physik, 55, 1-27 (in German).

Milankovitch, M. (1910). "Zu der Statik massiven Widerlager." Zeitschrift für Mathematik und Physik, 58, 120-128 (in German).

Moseley, H. (1843). The mechanical principles of engineering and architecture, Longman's London.

Navier, C. M. L. (1839). Resumé des Leçons donnés à l'Ecole des Ponts et Chaussés sur l'Application de la mécanique à l'etablissement des constructions et des machines, 2nd Ed., De Mortier, Brussels, Belgium (in French).

Ochsendorf, J. A. (2002). "Collapse of masonry structures." PhD thesis, Dept. of Engineering, Univ. of Cambridge, Cambridge, U.K.

Persy, N. (1834). Cours de stabilité des constructions à l'usage des Éléves de l'Ecole d'application de l'artillerie et du Génie, Lithographie de l'Ecole d'Application, Metz, France (in French).

Pinto, A., Molina, J., Pegon, P., and Renda, V. (2001). "Protection of the cultural heritage at the ELSA Laboratory." Historical Constructions 2001, Proc., 3rd Int. Seminar, Guimaraes, P. B. Lourenço and P. Roca, eds., Univ. do Minho, Portugal, 973-982.

Rankine, W. J. M. (1863). A manual of civil engineering, 2nd Ed., Griffin Bohn, London, U.K.

Rankine, W. J. M. (1864). Manual of applied mechanics, 3rd Ed., Charles Griffin, London.

Seguin. (1826). "Expériences sur la pesanteur spécifique et la résistance au renversement de bâtisse." Des ponts en fil de fer, Bachelier, Paris (in French).

Vicat, L. J. (1832). "Influence du mode d'attache des chaines sur la résistance des ponts suspendus." Ann. Ponts. Chaussees, 49, Paris, 394-397 (in French).

Walther, F. (1855). "Praktisches verfahren zur construction der mittellinie des drucks in Tonnengewölben." Zeitschrift für Bauwesen, 5, 383392 (in German). 